This item was submitted to Loughborough's Research Repository by the author.

Items in Figshare are protected by copyright, with all rights reserved, unless otherwise indicated.

\title{
Linking employee behaviour to external customer satisfaction using quality function deployment
}

PLEASE CITE THE PUBLISHED VERSION

PUBLISHER

(C) IMechE / Professional Engineering Publishing

\section{VERSION}

VoR (Version of Record)

\section{LICENCE}

CC BY-NC-ND 4.0

\section{REPOSITORY RECORD}

Hanna, Victoria, C.J. Backhouse, and Neil D. Burns. 2019. "Linking Employee Behaviour to External Customer Satisfaction Using Quality Function Deployment”. figshare. https://hdl.handle.net/2134/4579. 
This item was submitted to Loughborough's Institutional Repository (https://dspace.lboro.ac.uk/) by the author and is made available under the following Creative Commons Licence conditions.

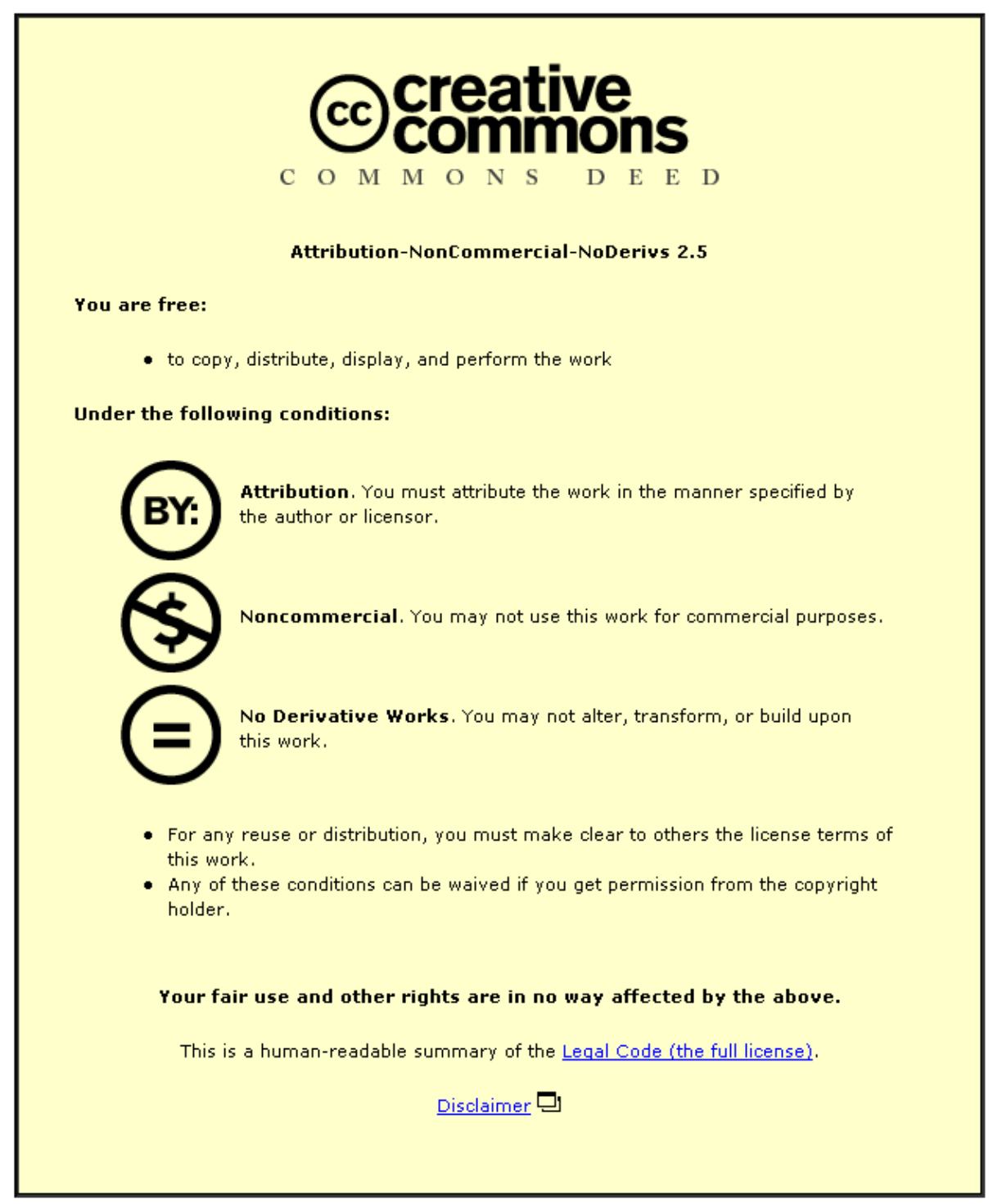

For the full text of this licence, please go to: http://creativecommons.org/licenses/by-nc-nd/2.5/ 


\title{
Linking employee behaviour to external customer satisfaction using quality function deployment
}

\author{
V Hanna ${ }^{1}$, C J Backhouse ${ }^{2}$ and N D Burns ${ }^{2 *}$ \\ ${ }^{1}$ Department of Management, University of Canterbury, Christchurch, New Zealand \\ ${ }^{2}$ Loughborough University, Loughborough, Leicestershire, UK
}

\begin{abstract}
This paper considers the relationship between human behavioural patterns occurring in industrial environments to the general level of external customer satisfaction, the hypothesis being that by correlating behaviour patterns to levels of customer satisfaction a route can be found to improve performance by changing behaviours. A modification of the quality function deployment (QFD) technique is used to relate attributes that external customers value to internal behavioural patterns. Situation strength is seen as the key influencing factor on individual and group behaviour, the argument being that, if the situation is strong, then changes to situational variables would have the primary impact upon the behaviour. In contrast, if the situation is weak, then recruitment and a rewards system are better influencers of behaviour. A case study based around a small engineering enterprise demonstrates how the use of QFD can guide managers on the introduction of the most appropriate initiatives to improve performance.
\end{abstract}

Keywords: employee behaviour, external customer satisfaction, quality function deployment

\section{INTRODUCTION}

In any manufacturing organization there are a wide variety of behaviour patterns that can occur, where behaviour patterns are defined as the various sequences of actions carried out by individuals and groups within an organization. Some of these behaviours are role specific and the behaviour depends upon role expectations, learnt patterns of behaviour, degree of training, nature of performance metrics, reward structures and specificity of instructions. Some behaviours are ritualistic such as those exhibited at formal events where the patterns of behaviour are often highly prescribed by the organization, by tradition or by other powerful agencies. There may also be displaced behaviours where the individual or group displace behavioural actions from a highly controlled situation where there is not much opportunity to express any other behaviour than the role behaviour. In contrast, there are other situations where there is more ambiguity and the individual has considerable discretion about how to behave. This may well be particularly true for non-role specific behaviours.

The MS was received on 18 February 2004 and was accepted after revision for publication on 5 May 2004.

*Corresponding author: Wolfson School of Mechanical and Manufacturing Engineering, Loughborough University, Loughborough, Leicestershire LE11 3TU, UK. E-mail: N.D.Burns@lboro.ac.uk

\subsection{Situation strength}

In classifying the various forms of behaviour the concept of situation strength [1] is valuable. In a strong situation there is little ambiguity in decision making and the situation controls the behaviour rather like red traffic lights control driving behaviour. This is common in highly role specific behaviour where standard operating procedures or target drivers control behaviour. Additionally, where there are established group norms of behaviour there is a powerful influence on a new member of a group to conform to group norms, thus creating a selfsustaining strong situation. These group norm situations can be both constructive and destructive depending on circumstances. They can lead to an environment of motivated internal striving for excellence or, on the negative side, they can lead to conspiratorial them-and-us situations typified by pacing - the deliberate slowing down of work output in order to maintain the image of looking busy. This situation is strong because all the individuals including new recruits quickly adopt the same behaviour patterns.

In the weak situation there is more ambiguity and individual discretion is important. These situations are typically found either where the organization requires agility to react quickly to unpredictable demands or where a rapidly growing company has not yet implemented set procedures and processes. In such weak 
situations learnt patterns of behaviour, motivation levels and experience all strongly influence behaviours. The influence of these factors diminishes as weak situations are moved to become stronger. Strength of situation will not be static. Individuals who prefer to operate in a weak situation will work to modify their own situation. While they may succeed in creating a weak situation for themselves, this may be at the expense of strengthening the situation for colleagues, especially those junior to themselves.

\subsection{Individual behaviour patterns}

Behaviour patterns are often regular repeating sequences of actions. Robertson [2] identified four types of factor that influence behaviour in the workplace. These are shown in Table 1. Other workers have also proposed similar groupings of variables that have significant influence on behaviour [3-6].

The behaviours of individuals can be identified as a response to influencing factors across the spectrum of strong to weak situations. In addition it has been recognized that the behavioural responses can be grouped into repeating patterns. Researchers such as Ashforth and Lee [7], Jaworski and Young [8], Merchant [9], Porras and Hoffer [10] and Vardi and Wiener [11] have all grouped behaviour patterns into repeating sets. They have particularly focused on those that are considered to be negative patterns in terms of organizational performance so that they can be identified and removed.

Intuitively it would seem obvious that positive behaviours would further the aims of the organization and negative patterns would be destructive. Goodman and Dean [12] and Tannenbaum [13] suggested that performance is a function of the aggregate behaviour of its employees. An extension of this concept is that organizational performance can only be irrevocably improved when employee behaviour is improved. However, there are many influencing variables that affect business performance and it is difficult to draw a direct causal link between behaviour and performance. It is the purpose of this paper to review this causal link between behaviours that are positive for the organization to policy domains in

Table 1 Factors influencing behaviour in the workplace

\begin{tabular}{ll}
\hline Social & Individuals' characters \\
& Group characteristics \\
& Organizational culture \\
Tangible features & Working environment \\
Physical setting & Work flow \\
& Technical expertise \\
& Job content \\
Organizing arrangements & Formal goals \\
& Strategies \\
& Structures \\
& Rewards system \\
\end{tabular}

Proc. Instn Mech. Engrs Vol. 218 Part B: J. Engineering Manufacture the business that can be adjusted to improve performance through varying the situational context.

\subsection{Organizational behaviour patterns}

The organizational behaviour literature typically focuses on four aspects of behaviour:

(a) productivity,

(b) absenteeism,

(c) staff turnover and

(d) job satisfaction.

These four behaviours can be described as outcome behaviours. They have characteristically been measured in organizational change research. Relevant papers include those by Orpen [14], Pate et al. [15] and Paul and Cross [16].

In contrast with outcome behaviours there are a set of behaviour patterns known as workstyle or on-the-job behaviours (OJBs) which have been shown to be associated with positive organizational outcomes, i.e. improved performance [10]. Research into specific OJB patterns is relatively infrequent but has been extensively discussed by Robertson et al. [17]. In her doctoral thesis, Hoffer [18] found, the more frequently these OJBs were observed, the more effective the organization. Two categories were defined: behaviours found at all organizational levels and those found at a managerial level, shown in Table 2.

In Hoffer's doctoral study, 36 organizations were examined for the perceived frequency of the OJBs and the performance of the business measured by six financial measures. The correlation between the workstyle behaviours and the financial measures was very significant. There was also a strong correlation between OJBs and job satisfaction, but no correlation between OJBs and rate of employee turnover [18].

\subsection{Prosocial behaviours}

There are other behaviour patterns that have been shown to promote organizational effectiveness; these are termed prosocial behaviours, which can be individual or

Table 2 Organizational and managerial OJBs

\begin{tabular}{ll}
\hline All organizational levels & Managerial level \\
\hline Communicating openly & Generating participation \\
Collaborating & Leading by vision \\
Taking responsibility & Functioning strategically \\
Maintaining a shared vision & Promoting information flow \\
Solving problems effectively & Developing others \\
Respecting/supporting & \\
Role flexibility & \\
Inquiring & \\
Experimenting & \\
\hline
\end{tabular}


organizational [19-21]. These have been described as behaviours that go beyond normal role requirements, e.g. behaviours such as taking action to protect the organization from unexpected danger, suggesting ways to improve the organization and speaking favourably about the organization to outsiders. These are behaviours that are observed within organizations but they cannot be considered to be task related and will not be called OJBs. All these behaviours enhance an organization's ability to survive and reach its goals. Brief and Motowidlo [19] have defined a set of prosocial behaviours as follows:

(a) assisting co-workers with job-related matters;

(b) assisting co-workers with personal matters;

(c) showing understanding in personnel decisions;

(d) providing services or products to customers in a consistent manner;

(e) providing services or products to customers in an inconsistent manner;

(f) helping customers with personal matters;

(g) complying with organizational values;

(h) suggesting improvements;

(i) objecting to improper directives;

(j) putting extra effort into the job;

(k) volunteering for extra assignments;

(l) staying with the organization;

(m) representing the organization favourably.

\subsection{Defensive OJBs}

In the field of organizational politics Ashforth and Lee [7] have developed a catalogue of defensive behaviour in organizations. Defensive behaviour is the reactive defence of self-interest. These OJBs enable individuals to reduce a perceived threat or to avoid unwanted demands. Three categories are defined and within these there are 14 specific OJBs, which are listed in Table 3.

This work is unique as previous work in this field concentrated on proactive actions such as negotiation, ingratiating and persuasion [22, 23].

\subsection{Financially linked OJBs}

A limited number of observed behaviour patterns in the work place were found in the behavioural accounting literature. The earlier work in the field revolved around

Table 3 Defensive OJBs

\begin{tabular}{lll}
\hline To avoid action & To avoid blame & To avoid change \\
\hline Over conforming & Bluffing & Resisting change \\
Passing the buck & Playing safe & Protecting turf \\
Playing dumb & Justifying & \\
Depersonalizing & Scapegoating & \\
Smoothing and stretching & Misrepresenting & \\
Stalling & Escalating & \\
& commitment & \\
\hline
\end{tabular}

B02804 (C) IMechE 2004 the behavioural aspects of budgeting and peoples' responses to incentives. Much of the subsequent work in the field has focused on standard setting, motivation and performance [24].

Merchant [9] has identified several OJBs:

(a) behaviour displacement, e.g. the folly of hoping for A while rewarding B;

(b) gamesmanship, i.e. actions that improve measures of performance without producing any positive economic effects, e.g. the creation of slack resources or data manipulation;

(c) negative attitudes, e.g. job tension, conflict and frustration;

(d) operational delays, e.g. as encouraged by excessive bureaucracy.

In conjunction with Chow and Kato, Merchant has also investigated the impact of organizational controls on management myopia, where myopia is an excessive focus on short-term issues [25]. Jaworski and Young [8] have also examined behaviour in the work place but they focus on managerial behaviour. They investigate when managers:

(a) gamed performance indicators,

(b) manipulated information flows and

(c) falsified data.

Although the behaviour patterns described above are OJBs, they are not sufficiently different from the empirical work of Ashforth and Lee [7], discussed earlier in this paper and included as separate OJBs. For the same reason the behaviours that have been linked to successful Kaizen implementation by Caffyn [26] are not considered as separate OJBs in this study.

\subsection{Organizational misbehaviour}

Vardi and Wiener [27] have identified three organizational 'misbehaviours'. They defined misbehaviour as 'any intentional action by members of organizations that violates core organizational or societal norms' and produced three variations on this theme:

(a) misbehaviour to benefit self;

(b) misbehaviour to benefit the organization;

(c) misbehaviour to inflict damage.

This work is closely linked with generating a new theory of motivation. Unfortunately definitions for the type of actions that fall into these three categories are not suggested. The work examines the relationship of personal factors such as personal need satisfaction and moral development, and organizational factors such as organizational culture and cohesiveness. Although innovative, this work is aligned very closely to the cognitive aspects of motivation and behaviour, and the behaviours are too loosely defined to benefit this research. In 
addition, misbehaviours may be considered as separate from other OJBs since it is a deliberate contravention of norms and procedures. They are not therefore considered in this paper.

\section{WORKPLACE VARIABLES INFLUENCING OJBS}

The set of OJBs as defined and collated in this paper are shown in Table 4. An individual's response to a situation is influenced by many variables. These factors can be summarized into three groups:

(a) internal factors, i.e. factors personal to the individual;

(b) external factors, i.e. factors that influence the individual;

(c) system factors, i.e. organizational structure and design factors.

\subsection{Internal factors}

Internal factors are those which are personal to the individual. They include variables such as personality, attitude and values. Personality has been described as 'those relatively stable and enduring aspects of the individual which distinguish him/her from other people and at the same time form the basis for our predictions concerning future behaviour' [28]:
1. The concept of a locus of control is considered to be a dimension of personality [29]. This theory assumes that people will differ in their attitudes to control. Externals feel that forces and events external to themselves control the outcome of their efforts whereas internals are convinced that control is an internal matter related to their own efforts and talents. Consequently, an individual will behave very differently within the confines of a performance measurement system depending on the nature of their locus of control.

2. An attitude is an opinion of the advantages and disadvantages of behaviour [30]. This belief is influenced by the recall of thoughts and associations from memory. It is a good predictor of behaviour and is incorporated into many of the theories of motivation.

3. Values are the basic convictions that a specific mode of conduct is personally or socially preferable to an opposite mode of conduct or end state. These values will be ranked according to their relative importance in a value system. Values will influence attitudes.

\subsection{External factors}

External factors that influence an individual include group norms, the prevailing culture and the leadership style:

1. The behaviour of a group is modified by shared norms, norms being standards of behaviour. Individuals are expected to conform to group norms and

Table 4 Typical OJBs

\begin{tabular}{|c|c|}
\hline OJB & Description \\
\hline Communicating openly & Behaviour promoting or reflecting the direct giving and receiving of information relevant to getting the job done \\
\hline Collaborating & $\begin{array}{l}\text { Behaviour promoting or reflecting the involvement of relevant persons in the processes of identifying and solving } \\
\text { problems }\end{array}$ \\
\hline Taking responsibility & Behaviour reflecting acceptance of responsibility and taking initiative in carrying out organizational tasks \\
\hline Maintaining a shared vision & $\begin{array}{l}\text { Behaviour reflecting a clear formulation, understanding and commitment to organizational philosophy, values } \\
\text { and purposes and a commitment to high standards }\end{array}$ \\
\hline Solving problems effectively & Behaviour reflecting a problem solving orientation to difficult organizational issues \\
\hline Respecting/supporting & Behaviour demonstrating respect and support for others as worthwhile individuals \\
\hline Role flexibility & Behaviour reflecting attention to and use of human process issues in one-on-one, group and intergroup situations \\
\hline Enquiring & Behaviour reflecting a probing enquiring diagnostic orientation to the organization and its environment \\
\hline Experimenting & Behaviour promoting or reflecting an openness to trying new things \\
\hline Over conforming & Avoiding action often by resorting to strict interpretation of responsibility or rules \\
\hline Passing the buck & Transferring responsibility for a task or a decision to someone else \\
\hline Playing dumb & $\begin{array}{l}\text { Individuals avoiding task by falsely pleading ignorance or inability; managers often playing smart and } \\
\text { pretending to be knowledgeable }\end{array}$ \\
\hline Depersonalizing & Treating other people as numbers or objects to distance oneself \\
\hline Stalling & $\begin{array}{l}\text { 'Foot-dragging' tactic to give the appearance of being more or less supportive publicly while doing little or } \\
\text { nothing privately }\end{array}$ \\
\hline Bluffing & Rigorously documenting activity or fabricating documents to project an image of competence \\
\hline Playing safe & An individual avoiding blame by evading situations that may reflect unfavourably on him or her \\
\hline Justifying & Developing explanations that reduce the individual responsibility for a negative outcome \\
\hline Scapegoating & Transferring responsibility, explanation for a failure or a negative attribution, upon an external factor \\
\hline Misrepresenting & Manipulating information by distortion, embellishment, deception or selective presentation \\
\hline Escalating commitment & Vindicating an initially poor decision by escalating support for the decision \\
\hline Resisting change & Catch-all for a variety of behaviours \\
\hline Protecting turf & Defending task domain from encroachment by others \\
\hline
\end{tabular}


are encouraged to do so by the use of rewards and sanctions. The overt use of pressure on individuals to comply can have negative implications [31] and can undermine the cohesiveness of the group.

2. Leadership is the ability to influence a group towards the achievement of goals. There are many different styles of leadership and each will affect an individual's ability to achieve those goals.

3. Organizational culture can be defined as a set of values that help people in an organization to understand which actions are considered acceptable and which are considered unacceptable [32].

4. Subcultures also exist within organizations. These can be attached to different roles, functions or levels of the hierarchy [33].

\subsection{System factors}

System factors are related to the organization's structure; they include the reward system and the performance measurement system. It is this interlinkage between incentives and measurement that is especially important. The closer that rewards can be tied to measures, the greater are the influence of the measures on behaviour. Their relationship to performance measurement system design is not clear but they certainly could be considered moderating factors. Behaviour patterns are a function of many variables, these include management style, prevailing culture, job situation, etc. An important ingredient in the mixture of variables that influence behaviour is the performance measurement and rewards system. This is also the variable over which many manufacturing organizations will have direct control.

\subsection{Effect of the individual}

Each of the above factors, namely internal, external and systems factors, will be moderated by the individual's personal experience and their ability to learn. Learning is the relatively permanent change in behaviour that occurs as a result of previous practice or experience [34]. (Learning is only observable through behaviour change and cannot be quantified directly.) Individuals who are sufficiently motivated can change their behaviour (i.e. learn) to improve their performance. The implication is that performance measurement systems should incorporate learning to enable maximum performance to be achieved.

\section{SYSTEM AND BEHAVIOUR FUNCTION DEPLOYMENT}

All companies want positive sets of behaviours but the complex situations and the multiple variables influencing behaviour inside the organization often interact to cause negative patterns. On the whole, companies want all the positive OJBs applied appropriately to increase business performance and the negative OJBs eliminated or at least minimized. The company can reinforce this message by explicitly relating the positive OJBs to the customerdesired attributes.

A useful tool in exposing organizational issues as they relate to OJBs is a modification of the quality function deployment (QFD) technique. In most circumstances, QFD relates the voice of the customer in terms of customer-desired product (physical or service) to design (physical or process) metrics. However, a modification of QFD is proposed in this paper, and is termed system and behavioural function deployment (SBFD). Behavioural qualities of the customer relationship that are valued are related to behavioural characteristics under the control of the company in order to design an overall behavioural policy which maximizes against ranked customer relationship qualities.

In contrast with traditional QFD the relationships in SBFD between customer attributes and behavioural characteristics are not identified as 'positive', 'neutral' and 'negative'. Instead they are ranked as 'strongly influencing', 'influencing' and 'neutral'. This is because in the behavioural domain it is not immediately recognizable which behavioural characteristics are positive or negative since they are completely context dependant. Only once the overall picture is developed and compared with competitor organizations can it be seen where the improvements in OJBs need to be targeted.

\subsection{Applying SBFD}

The first stages in developing the SBFD follow closely those of QFD. Thus the starting point is to identify and rank the behavioural attributes that are valued by customers. Following discussions with the customers these are ranked 1 to 5 . A 5 indicates that this is very important to the customer and has a direct influence upon their purchasing behaviour while a 1 indicates that they would like this attribute but it is not very important to them. The valued behavioural attributes together with the ranking of importance are shown in the two left-hand columns of the SBFD (Fig. 1) and correspond to the customer attributes in standard QFD. The next stage is to consider how the target company and its main competitors perform against these attributes. These are identified in the extreme right-hand column of the SBFD. Following this, the policy domains in the business that are judged to be controllable by the company and which can influence behaviours are identified and placed in the top row of the matrix. These correspond to the engineering characteristics of traditional QFD and are effectively a list of 'hows'. The central matrix is used to identify which policy domains affect which behavioural attribute. The 


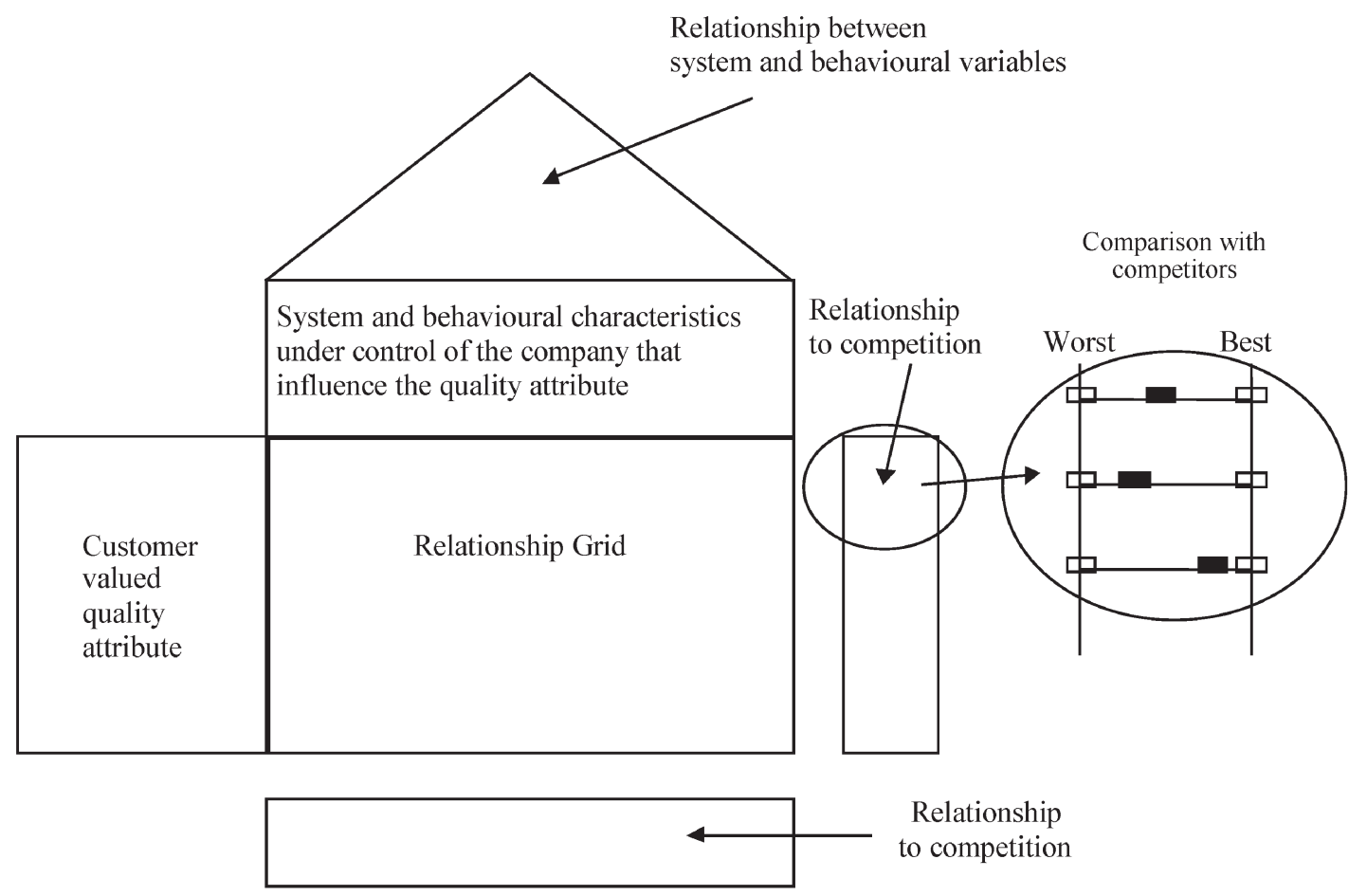

Fig. 1 The system and behaviour functional deployment

roof matrix is used to identify which policy domains affect each other.

The next stage in the development of the SBFD is to identify each of the company's policy domains within their spectrum of possible configurations (e.g. management style may range between participative and autocratic) and located relative to the competitor situation. The scale for this is a 'more or less than us' scale. For example, if the management style is command and control, then $\mathrm{a}+1$ indicates that the competitor is more command and control while a -1 indicates that they are less command and control. To indicate strong divergence, then +2 and -2 are used.

The information now available is a customer view of how the company's performance compares with its competitors. From this set of information the process of determining changes to policy domains in order to affect OJBs positively, and thus company performance, is progressed. This is best illustrated with reference to a case study which follows in the next section.

\subsection{Case study}

The case study concerns a company that recognized that changing behavioural policy domains would significantly improve the overall customer relationships. The company manufactured an engineered product that it sold on the international market. It was a long-established business that employed about 500 people at one main site. There was a high degree of variety in the products although there was a standard unit that was then customized. The SBFD was used by senior management as a guide to the issues that were hindering the adoption of more customer friendly relationships

\subsubsection{Application of SBFD}

The process of applying SBFD to this case study is summarized in the following steps.

Step 1. Customers were surveyed to determine how they perceived the service and behavioural performance of the business in comparison with that of the main competitors. A variety of issues emerged ranging from relatively 'hard' issues such as 'a responsive service' to softer issues such as a 'trusting relationship'. Customers had a clear perspective as to their priorities and how the business 'measured up' against its competitors. It is important to recognize at this stage that the present authors did not aim to elicit hard data on measurable indicators such as 'responsive service' since the concern was with qualitative customer supplier relationships based on customer perceptions. Table 5 shows the five behavioural requirements

Table 5 Customer behavioural requirements

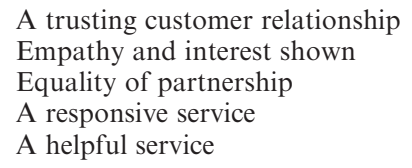

A trusting customer relationship

Empathy and interest shown

Equality of partnership

A responsive service

A helpful service 


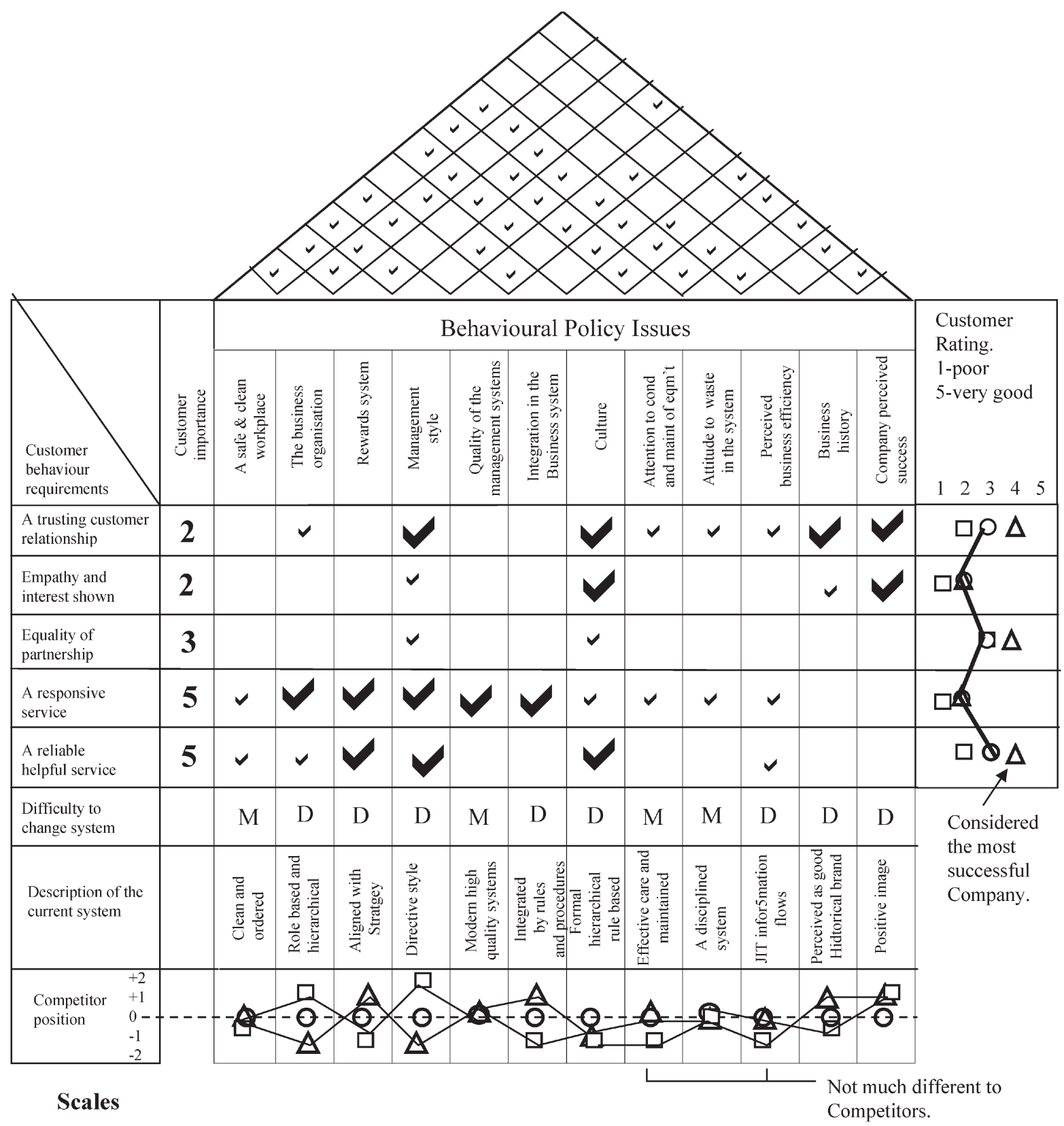

\begin{tabular}{|l|l|}
\hline Customer Importance & \multicolumn{1}{|c|}{ 1. - not important 5. very important. } \\
\hline Rating on chart & Strongly influencing $\checkmark$ influencing \\
\hline Difficulty of change & $\mathbf{D}$ - Very difficult change $\mathbf{M}$ - Medium difficulty \\
\hline $\begin{array}{l}\text { How good we are }- \\
\text { relative to competitor }\end{array}$ & 1. not very good 5 very good. \\
\hline Competitor position & $\begin{array}{l}\text { 0 indicates where we are. }+2 \text { indicates more than us and }-2 \\
\text { indicates less than us. For example, if we are command } \\
\text { and control +2 indicates they are more command and } \\
\text { control than us and }-2 \text { indicates that they are less. }\end{array}$ \\
\hline Roof of house of quality & $\checkmark$ Indicates a perceived relationship \\
\hline $\begin{array}{l}\text { Symbols for competitor } \\
\text { position and customer rating. }\end{array}$ & $\begin{array}{l}\Delta \text { and } \square \text { are symbols for competitors whilst } \bigcirc \text { is the } \\
\text { symbol for the case study company. }\end{array}$ \\
\hline
\end{tabular}

Fig. 2 SBFD 
Table 6 Rapid plant audit attributes on which behavioural policy domains were based

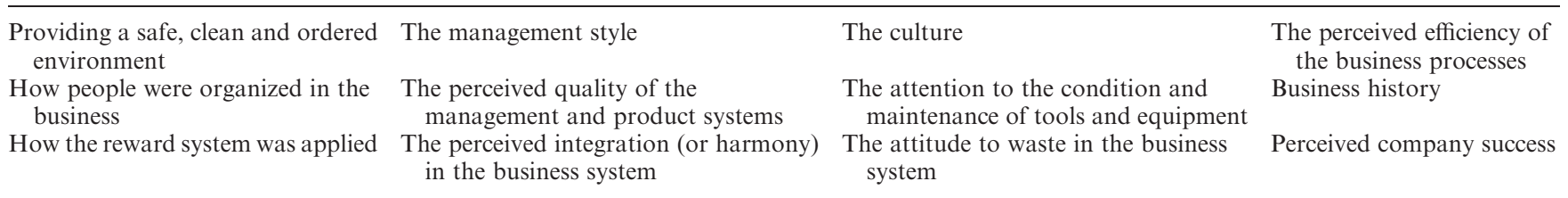

identified by the customers. These are included on the left-hand side of the SBFD shown in Fig. 2 where the rankings emerging from the customer survey are also shown. During the process of eliciting the qualitative data from the customers their views of how the company performed relative to the competitors was also identified. This enabled the right-hand column of the SBFD in Fig. 2 to be completed showing company performance relative to the competitors.

Step 2. Employees of the company were then involved in brainstorming behavioural policy domains that could be thought to influence customer perceived performance. This process was strongly informed by the rapid plant audit attributes described by Goodson [35]. The result of the brainstorming session was to identify 12 behavioural policy domains (Table 6). These behavioural policy domains were then included along the top of the main SBFD matrix. Each of these policy domains was considered in turn and their influence on customer behaviour requirements judged. The central matrix of the SBFD was then completed to show strong or medium influence, with no influence being indicated as a blank entry.

Step 3. The roof of the SBFD is then examined to identify where individual policy domains will interact with each other. The interactions are indicated as strong (positive or negative indicated by a tick) or neutral (no indicator). At this stage it is only possible to identify interactions, and not to identify whether these are positive or negative. The process followed to complete this stage mirrored that of step 2 where groups of employees considered each potential interaction in turn.

Step 4. The policy domains are now investigated individually to complete the lower part of the SBFD chart. Each domain is defined in terms of its spectrum (e.g. management style can be defined as potentially ranging from directive to participatory). The business was placed at the neutral point on the scale at the bottom of the chart (Fig. 2) and the main competitors compared with the company. On this value scale a ' + ' value indicated that the competitor had more emphasis on this area than the company while a '-' value indicated that the competitor was less so. For example, the perception of the business organization at the company was that it was hierarchical and some people used the words command and control. The most successful competitor was perceived as less hierarchical and more participative (negative indication) while the other competitor was as hierarchical and perhaps more so (positive indication). Finally a subjective estimate was then made as to the difficulty in changing any given policy domain based upon the perceived effort and resource requirements.

Step 5. The decision-making process is now based upon the presented information in the SBFD. The customer behaviour requirements are studied to see which need to be improved to meet or exceed competitor performance. The influencing behaviour policies can be identified from the SBFD matrix and it can be seen which need to be moved in their respective spectrum to achieve the required behaviour changes. The roof identifies interactions between policy domains allowing management to recognize where parallel initiatives are required. A consensual approach to developing targets ensures a coordinated action plan agreed by all staff.

\subsubsection{Behavioural policy issues}

The set of logic necessary to complete the SBFD is considerable and for reasons of space cannot be fully described in this paper. However, a selection of the identified issues, placed in a framework of the behavioural policy domains is described below.

The respondents were a sample of managers and people in the business at various levels in the company. They were asked by questionnaire to provide their perceptions of the following behavioural policy areas for their company and then to compare their perceived values with those of their main competitors.

1. Providing a safe, clean and ordered environment. The view of the respondents was that an environment that was demonstrated safe and clean primarily facilitated a reliable and responsive service. The consensus view was that all the significant competitors had a similar standard of safe and clean work place.

2. How people were organized in the business. The perception of respondents was that the formal company organization was unresponsive and bureaucratic. The business managers thought that the rules and procedures were becoming stifling and that it should be more flexible. The rather rigid structure was seen as having a negative effect upon the responsiveness of the service and the ability to set up empathetic and trusting relationships. The view 
was that the better performing competitor was less rigid in its organizational structure and supported more participation and sharing of knowledge in the business. However, it must be said that the better competitor was smaller and this may have helped them to have a more 'organic' organization.

3. How the reward system was applied. How rewards were distributed and perceived was identified as having a significant effect upon how the employees interacted with customers and how much they may be willing to enter into close and trusting relationships with them. The reward system was recognized as being highly susceptible to the 'law of unintended consequences' as identified by the many interactions in the roof matrix. Significant effort would need to be expended to change the system and it was therefore categorized in the SBFD as difficult to change. The company reward system was not felt to be well understood by employees while the best competitor seemed to have a more focused approach. The company felt that the poor understanding by employees of what would be rewarded led to some unintended OJBs.

4. The management style. The perception of this was that the primary management style encouraged in the business was directive rather than empowering. Combined with the perceptions of the organization and comparison with the performance of the best competitor the perception was that rules had to be relaxed and management had to be trained to become more facilitating, coaching and empowering if the best was going to be obtained from the people in the company.

5. The perceived quality of the management and product systems. The argument was that, if people perceive that they are working in a high-quality work space, it will influence their behaviour positively. An emphasis on quality of product and service was seen as a positive feature in improving quality of customer relationships. The perceptions of the people were that there was little to distinguish the company from competitors and they were felt to be all much the same.

6. The perceived integration in the business system. The view was that an integrated business, where people were pulling together to achieve business goals, would be capable of delivering a better service than its competitors. Although the business was better than the worst competitor, it was not seen as being as well integrated and operating to a strategic theme as the most successful competitor.

7. The culture. The perceived value system and the way that things were done in the business were considered in parallel to the business organization and the management style. The culture had developed as a consequence of a command-and-control management style and, as such, did not positively contribute to trusting customer relationships. The main competitors had a more relaxed and participative culture. Similar to the issues raised in the reward system the company felt that the directive nature of the company led to some undesirable OJBs.

8. The attention to the condition and maintenance of the tools and equipment. This was seen in a similar manner as the safe and clean environment. Primarily it was considered to affect the responsiveness and reliability of the system. The business was seen to be in an equivalent position to that of the best competition.

9. The attitude to waste in the business system. This was related to other policy issues but it was felt that it was important in its own right. It was thought that, if the people, organization structure and culture all reinforce a disciplined attention to detail, then a business that attempts to eliminate genuine waste in the product and service lead time would contribute significantly to improvements in customer requirements. It was difficult to obtain any distinction between the competitors and company for this and they are shown on the chart as having roughly the same values.

10. The perceived efficiency of the business processes. If the product flowed effectively and the systems in the company were perceived to be efficient, then it was thought that this would encourage efficient industry supportive behaviours by the people and consequently help to meet the customer requirements. However, this was strongly related to some of the other measures, e.g. attitude to waste and condition and maintenance of tools. How well the product flowed, the visibility and orderliness were all considered to be important with respect to the responsiveness and reliability of the service. The view of respondents was that this was about the same as the best competitor.

11. Business history. This important variable was seen to relate to the reputation and history of relationship that the business had established. While it may not be considered a directly controllable variable the secondary aspect of perception was seen as controllable. It was considered that the business had not done well in establishing positive relationships nor had it done well in convincing customers of a positive history. Some competitors were seen as having a better business history although whether this reflected reality or created perception was sometimes difficult to identify. This variable was strongly influenced by other variables such as business organization, culture and management style.

12. Perceived company success. It was considered that, if the company portrayed a positive image to its employees, then this would have an effect upon the relationships particularly in terms of how participative they would be. The perception was that the 
business would need to be more active in this area if they were to match the best competitor.

\subsubsection{Company targets for change}

In the early stages of the exercise the company had identified that its customers ranked a responsive service together with a helpful service as the most important behaviour attributes. It was in these two areas that the company was being significantly outperformed by its most successful competitor. In particular, it could be seen that, when customers considered the behaviour requirement for a reliable helpful service, the performance measured against the best competitor was poor. The behavioural policy issues that had the greatest effect on this behaviour requirement were the reward system, the management style and the culture.

The bottom row of the SBFD was then used to identify where significant differences between the company and its competitors existed in the key behavioural policy areas. It can be seen that there was significant difference in the areas of reward system management style and culture. The best competitor company had a far more participative and empowering culture. In contrast, it could be seen that the second competitor, which had performed less well in the area of a helpful service, had a strong controlling-type management style. These observations provided an initial conclusion that the behavioural policy issue on which to focus would be the management style and rewards system. It was felt that by focusing in this area the unintended OJBs could be minimized and would ensure that employee behaviour would be better aligned with company strategy.

The next stage was to consider the roof of the SBFD. Management style was interdependent with the business organization, the rewards system, the culture and the perceived success of the company. From the main matrix of the SBFD it could be seen that these behavioural policy issues had a significant impact on all customer behaviour requirements. It was necessary for the company management to understand whether changing their management culture to a more participative style would result in a negative impact on other behavioural policy issues and therefore be detrimental to some customer behaviour requirements. This issue required significant debate within the company and to a large extent had to be based on subjective judgement and experience. On the whole the consensus view was that the relationships could all be positive; i.e. that by changing the management style there would be positive benefit in all of the areas discussed above. However, it was recognized that, to ensure positive relationships management, the company needed to address all these areas to ensure policies aligned with a new management style and, where these did not exist, they would need to be changed. It was recognized that there was significant risk involved if all the behavioural policy issues were not considered in an holistic manner.
The overall conclusion of this part of the exercise was that there was a need to weaken situational controls on staff behaviour by giving the local managers much more discretion over decision making, effectively an empowering process. The current strong situation was creating undesirable OJBs at both the individual and the managerial levels, tending to move away from supportive OJBs to defensive OJBs. The objective for the business was to achieve more responsiveness by changing from a strong situation of hierarchical controls to a weaker situation where all employees would be empowered to exercise more discretion. The company recognized the need to identify the risks associated with doing this and to ensure action was taken in all areas where a relationship to management style existed, and especially in the rewards system which were seen as crucial to success.

To change the situation the company changed the management style from autocratic to more of a coaching style. It achieved this by introducing small cellular working into the business to improve local accountability and responsiveness. The cells were spread throughout the business and gave employees considerable discretion in controlling their own performance and working methods with gradually more and more autonomy being passed to them over a 2 year period. The company instigated a reward structure by introducing customer satisfaction performance components. It simplified the planning systems by giving more discretion in decision making to the employees directly involved with the various systems. These changes were effective in placing the point of decision making with the employees responsible for the tasks and situations. The total process lasted approximately 2 years. Change management was, as always, not easy. Many employees readily welcomed the changes but, as in the majority of such situations, some employees felt less comfortable. However, after 2 years the company repeated the evaluation of customer perceptions and from the results was confident that the changes that it had put in place had been of the correct type and had indeed delivered the desired effect.

\section{CONCLUSIONS}

There are many variables influencing the behaviour of individuals and groups in the working environment. Sometimes, particularly if there is a strong situation, a business may find that unintended OJBs have emerged are negative in terms of customer service. Such a business needs to be able to identify whether the consequence on customer service is serious, whether the competitors are doing better and, if so, what needs to be changed. The SBFD process described in this paper and strongly based on QFD has been shown to be a useful tool in both actioning and mapping decisions in this complex domain. 
Business can identify and change situations to remove drivers that are resulting in negative patterns and in parallel can encourage positive behaviours. The SBFD chart is a powerful tool for assessing how company policy domains are contributing towards customer satisfaction. It also aids the identification of actions that can improve the behavioural service given by people in the company. Finally, as in all consensus-generating management tools it is frequently the very act of business managers getting together and using the tool that creates most insight through the elimination of conflicting perceptions.

\section{ACKNOWLEDGEMENT}

The authors would like to acknowledge gratefully the support that the Engineering and Physical Sciences Research Council, UK, has extended towards them for this work.

\section{REFERENCES}

1 Mischel, W. The interaction of person and situation. In Personality at the Crossroads: Current Issues in Interactional Psychology (Eds D. Magnusson and N. Endler), 1977, Ch. 25 (Lawrence Erlbaum, Hillsdale, New Jersey).

2 Robertson, P. J. The relationship between work setting and employee behaviour. J. Organisational Change Managmt, 1994, 7(3), 22-43.

3 Klein, H. J. An integrated theory of work motivation. Acad. Managmt Rev., 1989, 14, 150-172.

4 Hunt, J. W. Managing People at Work, 3rd edition, 1992 (McGraw-Hill, London).

5 Pascale, R. T. and Athos, A. G. (McKinsey 7-S Framework) In the Art of Japanese Management, 1983 (Penguin Books, London).

6 Robey, D. Designing Organizations, 2nd edition, 1986 (Irwin, Homewood, Illinois).

7 Ashforth, B. E. and Lee, R. T. Defensive behaviour in organisations. Human Relations, 1990, 43(7), 621-648.

8 Jaworski, B. J. and Young, S. M. Dysfunctional behaviour and management control: an empirical study of marketing managers. Accounting, Orgn Soc., 1992, 17(1), 17-35.

9 Merchant, K. Organisational controls and discretionary program decision making: a field study. Accounting, Orgn Soc., 1985, 10(1), 67-85.

10 Porras, J. I. and Hoffer, S. J. Common behaviour change in successful organization development efforts. J. Appl. Behavioural Sci., 1986, 22(4), 477-494.

11 Vardi, Y. and Wiener, Y. Misbehaviour in organisations: a motivational framework. Orgn Sci., 1996, 7(2), 0151-0165.

12 Goodman, P. S. and Dean, J. W. Creating long term organisational change. In Change in Organisations (Ed. P. S. Goodman), 1982, pp. 226-279 (Jossey Bass, San Francisco, California).

13 Tannenbaum, R. Organisational change has to come from individual change. Innovation, 1971, 23, 36-43.
14 Orpen, C. The effects of job enrichment on employee satisfaction, motivation, involvement and performance. Human Relations, 1979, 32, 189-217.

15 Pate, L. E., Nielson, W. R. and Mowday, R. T. A longitudinal assessment of the impact of OD on absenteeism, grievance rates and product quality. Acad. Managmt Rev., Proc., 1977, 2, 353-357.

16 Paul, C. F. and Cross, A. C. Increasing productivity, and morale in a municipality: effects of organisational development. J. Appl. Behavioural Sci., 1981, 7(1), 59-78.

17 Robertson, P. J., Roberts, D. R. and Porras, J. I. Dynamics of planned organizational change: assessing empirical support for a theoretical model. Acad. Managmt Rev., 1993, 36(3), 619-634.

18 Hoffer, S. J. Behavioural and organizational performance: an empirical investigation. Doctoral Dissertation, School of Education, Stanford University, Stanford, California, 1986.

19 Brief, A. P. and Motowidlo, S. J. Prosocial organisational behaviours. Acad. Managmt Rev., 1986, 11(4), 710-725.

20 Smith, P. Outcome related performance indicators and organizational control in the public sector. Br. J. Managmt, 1993, 4, 135-152.

21 Smith, C. A., Organ, D. W. and Near, J. P. Organizational citizenship behavior: its nature and antecedents. J. Appl. Psychol., 1983, 65(4), 653-663.

22 Kipnis, D. and Schmidt, S. M. Profiles of Organisational Influence Strategies (POIS): Influencing your Manager, 1982 (University Associates, New York).

23 Mintzberg, H. Power In and Around Organizations, 1983 (Prentice-Hall, New York).

24 Young, M. In Behavioural Accounting Research: A Critical Analysis (Ed. K. R. Ferris), 1st edition, 1988 (Century VII, Columbus, Ohio).

25 Merchant, K. A., Chow, C. W. and Kato, Y. The use of organisational controls and their effects on data manipulation and management myopia: a Japan vs US comparison. Accounting Orgn Soc., 1996, 21(2-3), 175-192.

26 Caffyn, S. Continuous improvement in the new product development process. PhD thesis, University of Brighton, Brighton, 1998.

27 Vardi, Y. and Wiener, Y. Misbehaviour in organisations: a motivational framework. Orgn Sci., 1996, 7(2).

28 Wright, D. S., Davies, A., Sluckin, D. R., Lee, S. G. M. and Reason, J. T. Introducing Psychology: An Experimental Approach, 1970 (Penguin, London).

29 Rotter, J. B. Social Learning and Clinical Psychology, 1954 (Prentice-Hall, New York).

30 Ajzen, I. and Madden, J. T. Prediction of goal directed behaviour: attitudes, intentions and perceived behavioural control. J. Expl Social Psychol., 1986, 22, 453-474.

31 Chell, E. The Psychology of Behaviour in Organizations, 1987 (Macmillan, London).

32 Moorhead, G. and Griffin, R. W. Organisational Behaviour, 3rd edition, 1992 (Houghton Mifflin, Boston, Massachusetts).

33 Hampden-Turner, C. Cooperate Cultures, From Vicious to Virtuous Circles, 1990 (Random Century, London).

34 Robbins, S. P. Organizational Behavior: Concepts, Controversies and Applications, 6th edition, 1993, pp. 100, 110 (Prentice-Hall, Englewood Cliffs, New Jersy).

35 Goodson, G. http://webuser.bus.umich.edu/Organizations/ rpa/, 2002.

Proc. Instn Mech. Engrs Vol. 218 Part B: J. Engineering Manufacture 